\title{
BMI1, Stem Cell Factor Acting as Novel Serum-biomarker for Caucasian and African-American Prostate Cancer
}

\author{
Hifzur Rahman Siddique', Aijaz Parray ${ }^{1}$, Weixiong Zhong ${ }^{2}$, R. Jeffery Karnes ${ }^{3}$, Eric J. Bergstralh ${ }^{4}$, \\ Shahriar Koochekpour ${ }^{5}$, Johng S. Rhim ${ }^{6}$, Badrinath R. Konety ${ }^{7}$, Mohammad Saleem ${ }^{1,7,8_{*}}$
}

1 Molecular Chemoprevention and Therapeutics, The Hormel Institute, University of Minnesota, Austin, Minnesota, United States of America, 2 School of Medicine and Public Health, University of Wisconsin, Madison, Wisconsin, United States of America, 3 Department of Urology, Mayo Medical School and Mayo Clinic, Rochester, Minnesota, United States of America, 4 Division of Biomedical Statistics and Informatics, Mayo Medical School and Mayo Clinic, Rochester, Minnesota, United States of America, 5 Center for Genetics and Pharmacology, Roswell Park Cancer Institute, Buffalo, New York, United States of America, 6 Department of Surgery, Uniformed Services University of the Health Sciences, Bethesda, Maryland, United States of America, 7 Department of Urology, University of Minnesota, Minneapolis, Minnesota, United States of America, 8 Department of Laboratory Medicine Pathology, University of Minnesota, Minneapolis, Minnesota, United States of America

\begin{abstract}
Background: Lack of reliable predictive biomarkers is a stumbling block in the management of prostate cancer (CaP). Prostate-specific antigen (PSA) widely used in clinics has several caveats as a CaP biomarker. African-American CaP patients have poor prognosis than Caucasians, and notably the serum-PSA does not perform well in this group. Further, some men with low serum-PSA remain unnoticed for $\mathrm{CaP}$ until they develop disease. Thus, there is a need to identify a reliable diagnostic and predictive biomarker of CaP. Here, we show that BMI1 stem-cell protein is secretory and could be explored for biomarker use in CaP patients.

Methodology/Principal Findings: Semi-quantitative analysis of BMI1 was performed in prostatic tissues of TRAMP (autochthonous transgenic mouse model), human CaP patients, and in cell-based models representing normal and different CaP phenotypes in African-American and Caucasian men, by employing immunohistochemistry, immunoblotting and Slotblotting. Quantitative analysis of BMI1 and PSA were performed in blood and culture-media of siRNA-transfected and nontransfected cells by employing ELISA. BMI1 protein is (i) secreted by CaP cells, (ii) increased in the apical region of epithelial cells and stromal region in prostatic tumors, and (iii) detected in human blood. BMI1 is detectable in blood of CaP patients in an order of increasing tumor stage, exhibit a positive correlation with serum-PSA and importantly is detectable in patients which exhibit low serum-PSA. The clinical significance of BMI1 as a biomarker could be ascertained from observation that $\mathrm{CaP}$ cells secrete this protein in higher levels than cells representative of benign prostatic hyperplasia (BPH).

Conclusions/Significance: BMI1 could be developed as a dual bio-marker (serum and biopsy) for the diagnosis and prognosis of $\mathrm{CaP}$ in Caucasian and African-American men. Though compelling these data warrant further investigation in a cohort of African-American patients.
\end{abstract}

Citation: Siddique HR, Parray A, Zhong W, Karnes RJ, Bergstralh EJ, et al. (2013) BMI1, Stem Cell Factor Acting as Novel Serum-biomarker for Caucasian and African-American Prostate Cancer. PLoS ONE 8(1): e52993. doi:10.1371/journal.pone.0052993

Editor: Natasha Kyprianou, University of Kentucky College of Medicine, United States of America

Received October 23, 2012; Accepted November 27, 2012; Published January 7, 2013

Copyright: (c) 2013 Siddique et al. This is an open-access article distributed under the terms of the Creative Commons Attribution License, which permits unrestricted use, distribution, and reproduction in any medium, provided the original author and source are credited.

Funding: This work was in part supported by the Department of Defense CDMRP grant W81XWH-08-1-0605 to the corresponding author. The funders had no role in study design, data collection and analysis, decision to publish, or preparation of the manuscript.

Competing Interests: The authors have declared that no competing interests exist.

*E-mail: msbhat@umn.edu

\section{Introduction}

According to American Cancer Society, 241,740 will be diagnosed with prostate cancer $(\mathrm{CaP})$ and 28,170 $\mathrm{CaP}$ patients were projected to die in the year 2012 in USA alone [1]. The unsatisfactory outcome of overall management (treatment strategies and prognosis monitoring) for $\mathrm{CaP}$ disease could be associated to the lack of a reliable prognostic serum-biomarker. Although widely used, several important caveats have been reported in serum-PSA as a prognostic biomarker [2]. For example, in some $\mathrm{CaP}$ cases, serum-PSA is (a) detected little if any, (b) lacks adequate sensitivity, and (c) fails to discriminate potentially significant cancers from insignificant ones [2-4]. PSA does not reflect cancer biology and a high risk of mistaken results [5-6]. Further, discrepancies in PSA as a diagnostic marker among different racial groups such as Caucasians and African-American have confounded the management of this cancer [6-7]. Therefore a great need persists for the development of improved serologic biomarkers in $\mathrm{CaP}$, which is reliable for prognosis and diagnosis in Caucasian and African-American patients.

There is increasing evidence that polycomb group (PcG) proteins play a crucial role in cancer development and disease recurrence [8]. B-cell-specific Moloney murine leukemia virus integration site 1 (BMI) is a well-known marker used in stem cell biology [8-9]. BMI which has an ubiquitous pattern of expression in almost all tissues is frequently upregulated in various types of human cancers [8-10]. We recently reviewed significance of BMI1 in the emergence of chemoresistance in various types of cancers including $\mathrm{CaP}$ [8]. The current study is the first clinical 
evidence showing that BMI is a secretory protein that has tremendous potential to be developed as a serum-biomarker for $\mathrm{CaP}$ and its prognosis in both Caucasian and African-American population. We suggest that serum-BMI 1 as a biomarker would perform better than PSA. Further, BMIl could be used as a dual biomarker in serum as well as biopsy.

\section{Materials and Methods}

\section{Prostate tissues and Serum samples from human CaP patients}

Prostatic tissues surgically harvested from human CaP patients and matching paraffin blocks were procured from Cooperative Human Tissue Network Midwestern Division, The Ohio State University (Columbus, OH). Serum samples of human CaP patients were procured from serum bank (BioServe, Beltsville, MD). Additional paraffin-embedded sections of human prostate tissues of 70 patients with normal and adenocarcinoma were obtained from the ISU Abxis Co. Ltd., (Seoul, South Korea).

\section{Cell Lines}

Cell lines originated from both Caucasian and African American mans were used in our study. Normal and immortalized prostate epithelial cell line (RWPE1), CaP cell lines (LNCaP, C42b, PC3, Dul45, VCaP and PCa-2b), prostatic stromal myofibroblasts (WPMY1), colon normal epithelial cells (FHC) and colon cancer cell lines (SW480, HCT116 and HT29) and human pancreatic carcinoma cell lines PANC1 and AsPCl were obtained from ATCG (Manassas, VA). Normal pancreatic ductal epithelia cells, premalignant Kras mutant E6E7-Ras and malignant Kras mutant E6E7-Kras-st cells were obtained from D. Paul M. Campbell (H. Lee Moffitt Cancer Center, Tampa, FL) [11]. BPH-1 cells were procured from Dr. Simon Hayward (Vanderbilt University, Nashville, TN) who developed them as described [12]. Establishment and characterization of RC77N/E, RC77T/E and E006 cells was described earlier [13-14]. Cells were grown in appropriate media supplemented with 10\% FBS (ATCG, Manassas, VA) and 1\% Penicillin-Streptomycin (Invitrogen, Carlsbad, CA) under standard cell culture conditions of $5 \% \mathrm{CO}_{2}$ in an incubator at $37^{\circ} \mathrm{C}$.

\section{Cell Selection}

(a) Caucasian Cells: RWPE1 (normal), BPH-1 (non-malignant hyperplasia) and, LNCaP, C4-2B, PC-3, Dul45 and VCaP representing Caucasian prostate cancer. WPMYIl stromal fibroblasts were also used. (b) African American Cells: RC77N/E (normal), and RC77T/E, PGa-2B, E006 representing African American prostate cancer.

\section{Antibody, Plasmids and siRNA}

Monoclonal anti-BMI1 antibody was procured from Millipore (Temecula, CA). pbabe-BMIl plasmid (BMI1-overexpressing) was a kind gift from Dr. Chi V. Dang (The John Hopkins University, Baltimore, MD). BMI1-siRNAs were commercially purchased from Dharmacon (Lafayette, CO).

\section{Immunohistochemistry}

Immunohistochemical staining was performed as described earlier [15-16]. Briefly, paraffin sections (to be evaluated for BMI1) were pretreated with citrate buffer $(\mathrm{pH}$ 6) for $10 \mathrm{~min}$ in a microwave for antigen retrieval. Sections were incubated with primary antibody (anti-BMI) at a dilution of 1:50 for $12 \mathrm{~h}$ at $4{ }^{\circ} \mathrm{C}$. Slides were then incubated for $2 \mathrm{~h}$ at room temperature with appropriate HRP-conjugated secondary antibody. Slides were developed in 3, 3'-diaminobenzidene (DAB kit, Invitrogen, Carlsbad, CA) and counter stained with hematoxylin. The stained slides were dehydrated and mounted in permount solution under cover slips.

\section{Western blot Analysis}

Immunoblots analysis was performed as described earlier [1617]. Briefly, cell lysates were prepared in cold lysis buffer [(0.05 mmol/L Tris-HCl, $0.15 \mathrm{mmol} / \mathrm{L} \mathrm{NaCl}, 1 \mathrm{~mole} / \mathrm{L}$ EGTA, $1 \mathrm{~mol} / \mathrm{L}$ EDTA, $20 \mathrm{mmol} / \mathrm{L} \mathrm{NaF}, 100 \mathrm{mmol} / \mathrm{L} \mathrm{Na} 3 \mathrm{VO} 4,0.5 \%$ NP-40, 1\% Triton X-100, 1 mol/L phenyl methylsulfonyl flouride $(\mathrm{pH} 7.4)]$ with protease Inhibitor Cocktail (Roche, Indianapolis, IN). The lysate was collected and stored at $-80^{\circ} \mathrm{C}$. The protein content in the lysates was measured by BCA protein assay (Pierce, Rockford, IL), as per the vendor's protocol. For Western blot analysis, $40 \mu \mathrm{g}$ protein was resolved in 10\% SDS-PAGE gels, transferred onto PVDF membranes (Millipore, Bedford, MA) and subsequently incubated in blocking buffer (5\% nonfat dry milk/ $1 \%$ Tween 20; in $20 \mathrm{mmol} / \mathrm{L} \mathrm{TBS}, \mathrm{pH} 7.6)$ for 2 hours. The blots were incubated with BMI1 primary antibody, washed and incubated with HRP-conjugated secondary antibody (Sigma, Saint Louise, MO). The blots were detected with chemiluminescence (ECL kit, Amersham Biosciences, Piscataway, NJ). Equal loading of protein was confirmed by stripping the blots and reprobing with $\beta$-actin (Sigma, St. Louis, MO). Densitometry measurements of the scanned bands were performed as described earlier [16].

\section{Detection of Protein in cell culture media}

Cells were allowed to grow up to $80 \%$ confluence in complete media. At $80 \%$ confluent level, media was discarded and cells were washed with PBS twice. After washing, cells were added with serum-free media. Cells were cultured in serum-free media for $24 \mathrm{~h}$. After $24 \mathrm{~h}$, media was collected and analyzed for BMIl secretory protein by using Immuno-Slot-blot assay. The Slot-blot assay was performed as per the manufacturers' protocol (Whatman, Florham Park, NJ). Briefly, Slot-blot apparatus was assembled using Whatman filter paper and a pre-wetted nitrocellulose membrane. Next, the apparatus was connected to a vacuum pump. Slots were filled with samples (media/serum) and then drawn by vacuum (unused slots were filled with PBS). The membranes were then blocked for $2 \mathrm{~h}$ in blocking buffer $(5 \%$ nonfat dry milk). The blots were incubated with BMIl primary antibody, washed and incubated with HRP-conjugated secondary antibody (Sigma, Saint Louise, MO). The blots were detected with chemiluminescence (ECL kit, Amersham Biosciences).

\section{Removal of Albumin from serum samples}

Albumin was removed from human serum samples by using Albumin Removal Kit (Pierce, Rockford, IL) as per vendor's protocol. Samples containing $1000 \mu \mathrm{g}$ of total protein were loaded onto a single removal disc, where each disc is reported to have a binding capacity of $>2 \mathrm{mg}$ of albumin.

\section{Estimation of PSA protein levels by ELISA}

This was performed by using human PSA-specific ELISA (Anogen, Ontario, Canada) as per vendor's protocol.

\section{Quantification of secretory BMI1 protein in culture media}

This was performed by using a BMIl-specific ELISA (Antibodies-online Inc., Atlanta, GA). Recombinant BMI1 protein was used to serve as standard for this assay. 
BMI1-siRNA and pbabe-BMI1 (BMI1-expressing plasmid) transfection to validate that BMI1 is indeed secreted by CaP cells

Transfections were performed by using Lipofectamine (Invitrogen, Carlsbad, CA) as per vendor's protocol. For this reason, first intracellular BMIl from Caucasian CaP (LNCaP and Du 145) and African American CaP (E006) epithelial cells was determined.

Under $1^{\text {st }}$ approach. BMIl was knocked down by shRNA in Caucasian and African American cells. $12 \mathrm{~h}$ after transfection, cells were grown in complete media for $12 \mathrm{~h}$. After $24 \mathrm{~h}$ posttransfection, media was discarded and cells were grown in serumfree media for $24 \mathrm{~h}$. After $24 \mathrm{~h}$, serum-free media from BMIknockdown cells was collected and secreted-BMIl levels were measured by ELISA.

Under $2^{\text {nd }}$ approach. prostate cancer cells representing Caucasian and African American disease were transfected with BMIl-overexpressing plasmid. $12 \mathrm{~h}$ after transfection, cells were grown in complete media for $12 \mathrm{~h}$. After $24 \mathrm{~h}$ post-transfection, media was discarded and cells were grown in serum-free media for $24 \mathrm{~h}$. After $24 \mathrm{~h}$, serum-free media from BMIl-overexpressing cells was collected and secreted-BMIl levels were measured by ELISA.

\section{Androgen treatment of cells}

For this reason, Caucasian and African American prostate epithelial cells were treated with androgen analogue (R1881) for $12 \mathrm{~h}$. After $12 \mathrm{~h}$, media was discarded and cells were grown in further $12 \mathrm{~h}$. After $24 \mathrm{~h}$, cells were harvested to be evaluated for intracellular BMIl expression by western blot analysis.

\section{Statistical analyses}

Graphical summaries of the distribution of staining intensity were made using scatter plots and box plots. Simple linear egression and correlation methods were use to evaluate associations between BMI1, PSA and CaP rank ( $1=$ normal, $2=$ Stage II, $3=$ Stage III, $4=$ Stage IV). To correct for skewness, BMIl and PSA were analyzed on a $\log$ (base2) scale. A p-value of $<0.05$ was considered to be statistically significant.

\section{Results}

Bmi1 protein levels in prostatic tissues increases with progressive stages of disease in transgenic TRAMP mouse models

Glinsky et al. [18] previously showed that Bmil protein is elevated in the prostatic tissues of TRAMP mice, an autochthonous mouse model of $\mathrm{CaP}$ development, we investigated if a progressive increase in the levels of Bmil in prostatic tissues could be detected during progressive age of $\mathrm{CaP}$. For this purpose we used prostatic tissue samples collected at different ages of TRAMP transgenic mice. As shown in Fig 1A; Bmil protein was observed to be detectable in all ages of TRAMP mice. In general, the staining was stronger in prostatic epithelial cells from older mice than in prostatic epithelial cells from younger mice. Smooth muscle cells have much stronger staining than fibroblast cells. The staining pattern of Bmil protein was compared in age 17 weeks to 45 weeks old prostatic specimens (Fig. 1A). These data showed increased expression levels of Bmil protein in prostate of older aged mice (Fig. 1A). There was an intense staining at apical region of epithelial cells. Stromal regions were observed to have a positive staining (Fig. 1A).
BMI1 protein expression in prostatic tissue specimens of CaP patients

Notably, some epithelial cells of transgenic mouse prostate epithelial cells showed dense apical staining suggesting that Bmil could be a secretory protein. We next identified the expression of BMI1 in human CaP specimens by immunohistochemical analysis and determined its expression levels in stromal regions of 70 pairmatched specimens of normal and CaP representing all tumor stages. The intensity of immunoperoxidase staining for BMIl was scored as 0 (negative), 1 (weak), 2 (moderate) and 3 (strong). Immunostains showed staining in both non-neoplastic and neoplastic stroma. In general, the staining was stronger in neoplastic stroma than in non-neoplastic stroma. The epithelial cells also showed positive staining for the antibody (Fig. 1Bi). Smooth muscle cells have much stronger staining (3) than fibroblast cells $(0-1+)$. The staining pattern of BMI protein was compared in stage II-IV CaP specimens (Fig. 1Bi). These data showed increased expression levels of BMIl protein in high grade tumor in human CaP (Fig. 1Bi). The box plots of the data for BMI protein expression in stroma exhibited a wide interspecimen variation in cancer specimens, compared with normal tissues and revealed a significant difference in the level of protein between normal and $\mathrm{CaP}$ tissues $(\mathrm{p}<0.05$, Fig. 1Bii). The average score for the staining intensity of BMI 1 in stroma of normal tissues was $0.81 \pm 0.07(\mathrm{n}=70)$, and was significantly lower than highgrade stage II $(1.8 \pm 0.08 ; n=36)$, stage III $(2.26 \pm 0.10 \mathrm{n}=28)$ and stage IV $(2.8 \pm 0.11 ; \mathrm{n}=6)$ cancer specimens (Fig. 1 Bii; $\mathrm{p}<0.05)$. A similar pattern of staining in pair-matched CaP specimens was observed in the epithelial of the prostatic specimens. Taken together, these data show that expression of BMI increases with increasing stage of $\mathrm{CaP}$.

\section{BMI1 expression in normal and neoplastic prostatic cells representing CaP disease in Caucasian men}

As an attempt towards identifying the expression of BMI1 in $\mathrm{CaP}$ progression, we first measured protein expression levels by immunoblot analysis in several human Caucasian CaP cell lines, LNCaP, Du145 and PC3 and compared them to NHPE (normal primary prostate epithelial cell) and RWPE1 (representing normal immortalized prostatic epithelial cells), respectively. Among the $\mathrm{CaP}$ cell lines used, LNCaP is androgen-dependent whereas Du145 and PC3 are androgen-independent. The choice of these cells was based on the fact that $80 \%$ CaP patients present with androgen-dependent disease at the time of diagnosis which later transforms into more aggressive, androgen-independent disease [19]. As shown in Figure 2(Ai-ii), all CaP cell lines exhibited a higher expression of BMIl protein than in normal prostate epithelial cells. When the protein expression of BMIl was compared, based on the densitometric analysis of the immunoblots, highly aggressive PC3 cells and Du145 exhibited higher expression than in LNCaP cells (Fig. 2Aii). Interestingly, we also detected BMI 1 expression in the prostate stromal cells (WPMY1) (Fig. 2Ai-ii). Interestingly, BMIl expression was found to be very low in prostate epithelial cells representing benign prostatic hyperplasia (BPH) condition (data not shown).

BMI1 expression in normal and neoplastic prostatic cells representing $\mathrm{CaP}$ disease in Africa- American men

Age-adjusted data from SEER study showed that AfricanAmerican men have a 60\% higher incidence and 125\% higher mortality rates from CaP than Caucasian men [1,13]. Race and family history are the two most widely accepted risk factors for this disease [1]. Understanding the underlying biological mechanisms 

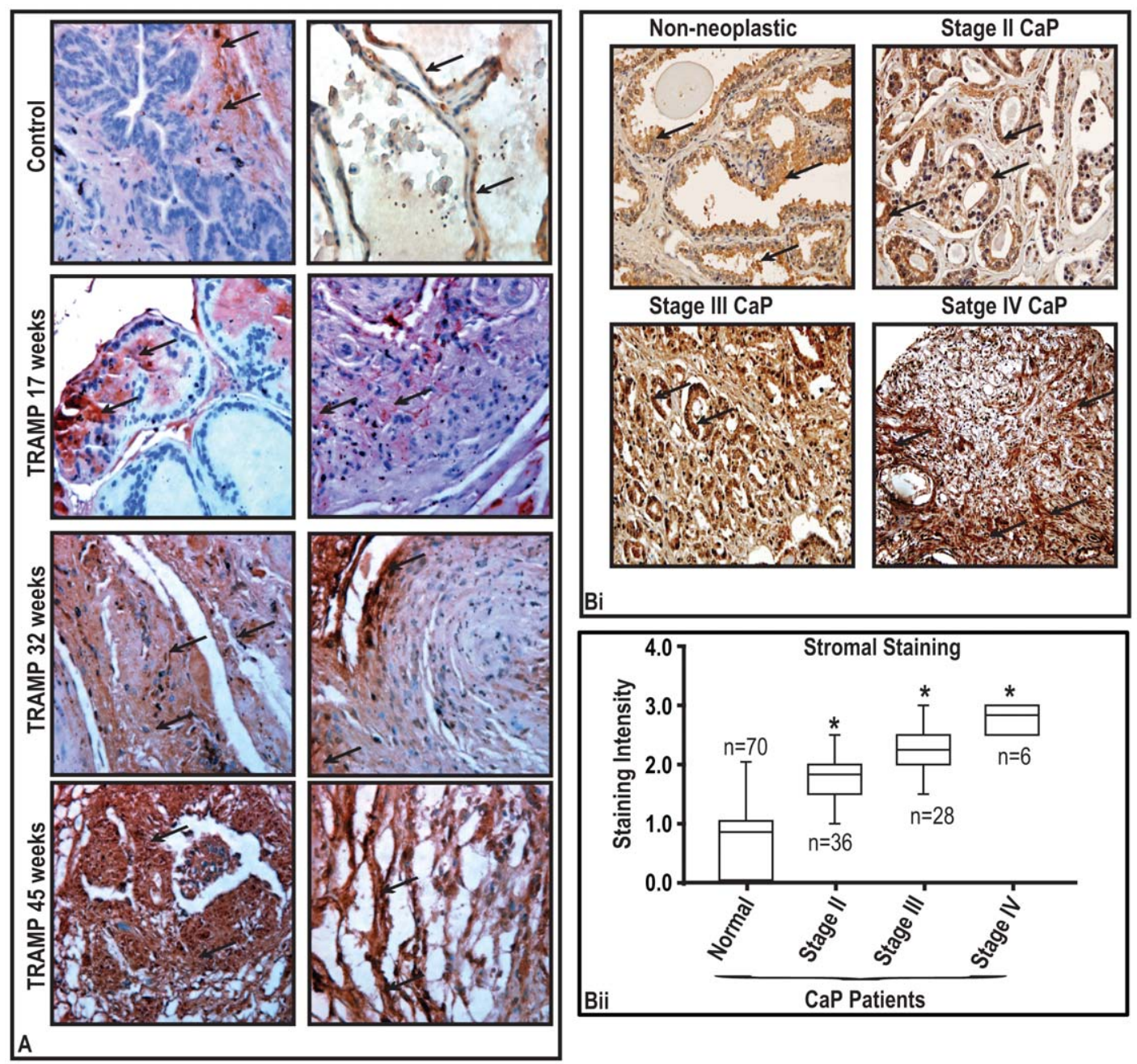

Figure 1. BMI1 protein levels in prostatic tumor tissues of humans and TRAMP transgenic mice. (A) Photomicrographs represent immunostaining of BMI1 in prostatic tissues of transgenic TRAMP mice. Arrows indicate staining for BMI1. Magnification $\times 40$. (Bi) Photomicrographs show BMI1-positive neoplastic and non-neoplastic regions of prostatic specimens of CaP patients as assessed by immunostaining. Arrows indicate staining for BMI1. Magnification $\times 40$. (Bii) Box plots for BMI1 protein based on score pertain to immunostaining pattern in normal and CaP specimens in stromal region.*, $\mathrm{P}<0.05$; black bar in box, median values.

doi:10.1371/journal.pone.0052993.g001

responsible for $\mathrm{CaP}$ progression will eventually lead to the development of more effective therapeutic strategies. We determined the levels of BMI1 expression in a cell-based in vitro model representing different phenotypes of $\mathrm{CaP}$ disease in AfricanAmerican men. These include RG77N/E (representing normal prostatic epithelial cells in African-American men), RG77T/E (representing androgen-dependent tumorigenic prostatic epithelial cells), E006 (representing androgen-dependent non-tumorigenic prostatic epithelial cells) and PCa-2b (representing CRPG phenotype; however retain androgen responsiveness) [13-14]. As shown in Figure 2(Bi-ii), all CaP cell lines RC77T/E, PCa2b and E006 exhibited a higher expression of BMI 1 protein than in normal cells RG77N/E. These data (Fig. 2A-B) suggest a possibility that expression of intracellular BMI protein may be correlated with the secretory BMIl levels in human tissues and may play a role in aggressiveness of human $\mathrm{CaP}$.
BMI1 is a secretory protein: Detection in serum-free media from $\mathrm{CaP}$ cell cultures

The presence of BMIl in the apical region of prostate epithelial cells and stromal region prompted us to hypothesize that it could be a secretory protein in nature. To test our hypothesis we asked if BMI1 is secreted by tumor cells under culture conditions. In order to detect BMI 1 protein in culture media of $\mathrm{CaP}$ cells, we employed Slot-blot technique. Cells at a confluency level of $80 \%$ were allowed to grow in fresh serum-free media for $24 \mathrm{~h}$. As evident from Fig. 2C, serum free media (harvested from CaP cells culture) tested positive for BMIl protein. Notably, media collected from cultures of epithelial cells representative of normal and $\mathrm{BPH}$ condition exhibited very low BMIl protein (Fig. 2C).

Quantification of secretory BMI1 in culture media of cells representing $\mathrm{CaP}$ in Caucasian and African-American men

By employing a human specific BMI1-ELISA technique, we were able to detect and quantify BMIl protein secreted by cells 

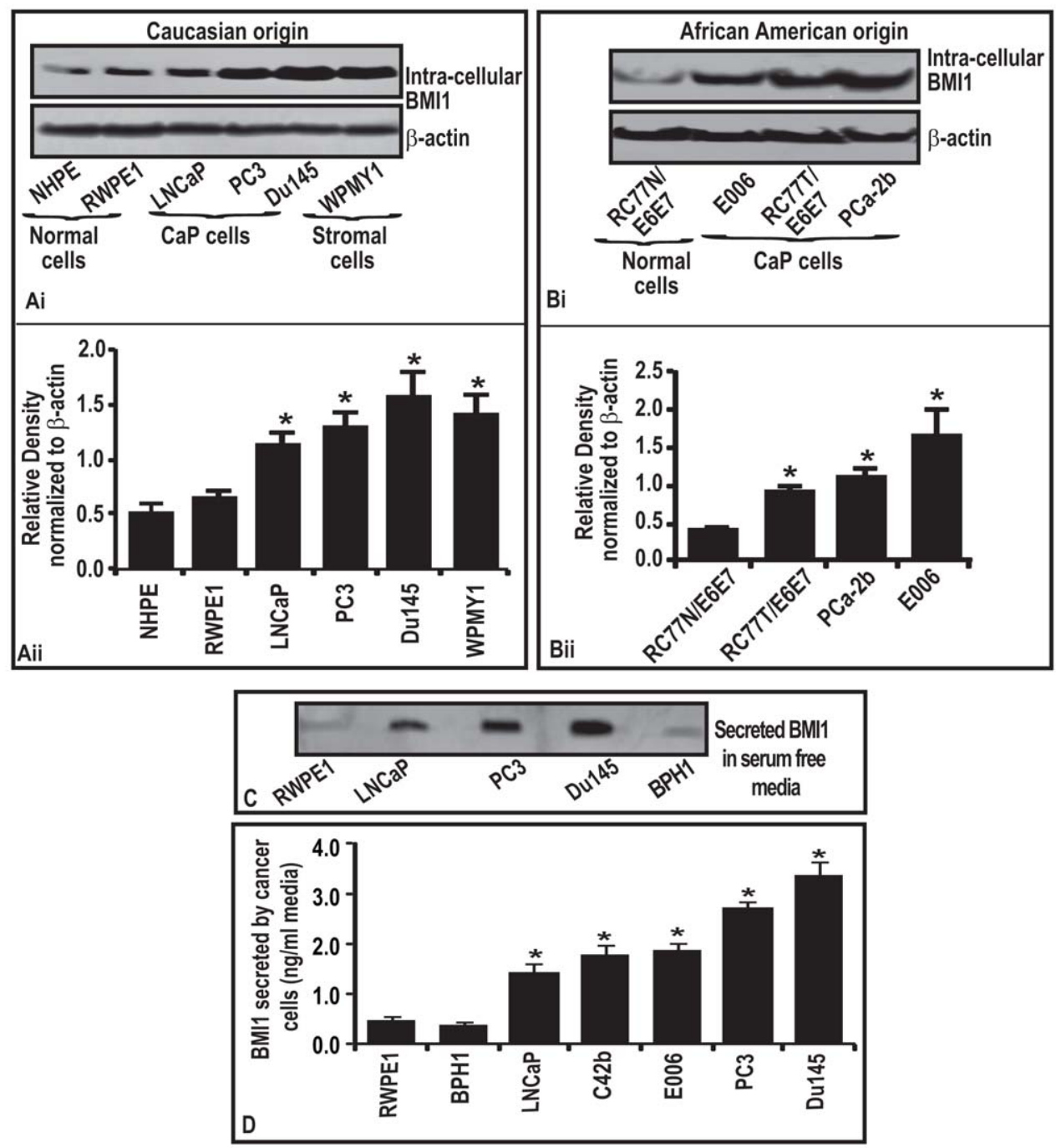

Figure 2. BMI1 protein levels (in both intracellular and secretory forms) correlate to the aggressiveness of tumor cell type representing Caucasian and African American CaP disease. (Ai) Figure represents the level of BMI1 protein in normal and CaP cells of Caucasian origin as assessed by immunoblot analysis. Equal loading of protein was confirmed by reprobing immunoblot for $\beta$-actin. The blot shown here are representative of three samples. (Aii) Histogram showing the densitometry analysis of immunoblots of BMI1. *, P $<0.05$; black bar in gray box, median values. (Bi) Figure represents the level of BMI1 protein in normal and CaP cells of African American origin as assessed by immunoblot analysis. Equal loading of protein was confirmed by reprobing immunoblot for $\beta$-actin. The blots shown here are representative of three samples. (Bii) Histogram showing the densitometry analysis of immunoblots of BMI1. ${ }^{*}, \mathrm{P}<0.05$; black bar in gray box, median values. (C) Figure represents the detection of BMI1 in conditional culture medium of different cells as assessed by Slot-blot analysis. The blots data shown here are representative of three samples. (D) Detection of secreted BMI1 protein in conditioned culture medium of cells. Each bar in the histogram represents mean \pm SE of 3 independent experiments, *represents $\mathrm{P}<0.05$.

doi:10.1371/journal.pone.0052993.g002

representing $\mathrm{CaP}$ in Caucasian and African-American men (Fig. 2D). We determined secreted BMIlprotein levels (a) in the culture media of normal, BPH1, and (b) in the culture media of tumor cells representing various cancer types. BMI1 was detected in the culture media of normal prostate cells (RWPE1; $0.45 \mathrm{ng} / \mathrm{ml}$ media) and interestingly the levels of BMIl were not elevated in BPH1 cells (Fig. 2D). As compared to normal RWPE1 cells, CaP cells exhibited increased secretory BMI1 protein levels in media (Fig. 2D). LNCaP, C42b, PC3 and Du145 cells were observed to secrete BMI protein in a range of $1.3-3.4 \mathrm{ng} / \mathrm{ml}$ of media (Fig. 2D). It is noteworthy that BMIl secreted protein was observed in the serum-free culture media of all types of CaP cell lines representing from normal RWPE1 to lesser aggressive LNCaP to castration-resistant prostate cancer (CRPC) cells
C42b through highly aggressive Du145 and PC3 cells. This finding corroborates with the data obtained $\mathrm{CaP}$ patients representing progressive stages of disease who were analyzed for serum-BMI1 protein levels. Notably, media collected from the cultures of epithelial cells E006 (derived from African American $\mathrm{CaP}$ patient) exhibited significantly high BMIl protein (Fig. 2D). On the contrary, the culture media of prostate stromal cells (WPMY1), normal colon epithelial cells (FHC) and normal pancreatic ductal epithelial cells (PDE) did not exhibit any secreted BMI levels (data not shown). Interestingly, secreted BMIl levels were not to be observed in all types of pancreatic (Kras-mutant PDE, E6E7-Ras and E6E7-Ras-st) and colon carcinoma cell lines (SW480, HCT116), but only in highly aggressive pancreatic cell lines AsPC1 (at very low levels; data not 

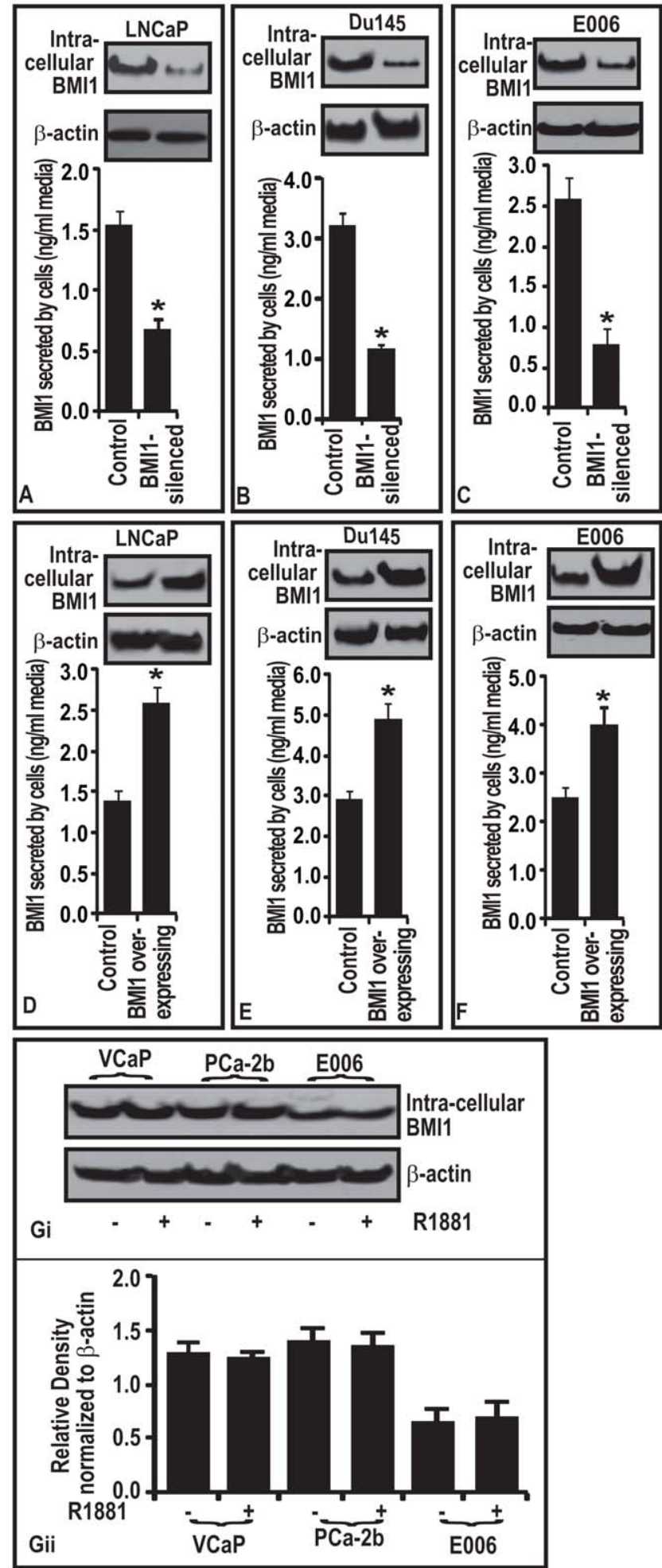

Figure 3. Secretory BMI1 is correlated with its intracellular levels in prostatic tumor cells and is independent of androgen. (A-F) Figure represents the effect of (A-C) BMI1-silencing and (D-F) BM11-overexpression on the level of secreted BMI1 protein in conditional media of different cells as assessed by ELISA assay. Equal loading of protein was confirmed by reprobing immunoblots for $\beta$ actin. Each bar in the histogram represents mean \pm SE of 3 independent experiments, ${ }^{*}$ represents $P<0.05$. (Gi) Figure represents the level of BMI1 protein in androgen (R1881) treated and non-treated $\mathrm{CaP}$ cells as assessed by immunoblot analysis. Equal loading of protein was confirmed by reprobing immunoblot for $\beta$-actin. (Gii) Histogram showing the densitometry analysis of immunoblots of BMI1. ${ }^{*}, \mathrm{P}<0.05$; black bar in gray box, median values. doi:10.1371/journal.pone.0052993.g003
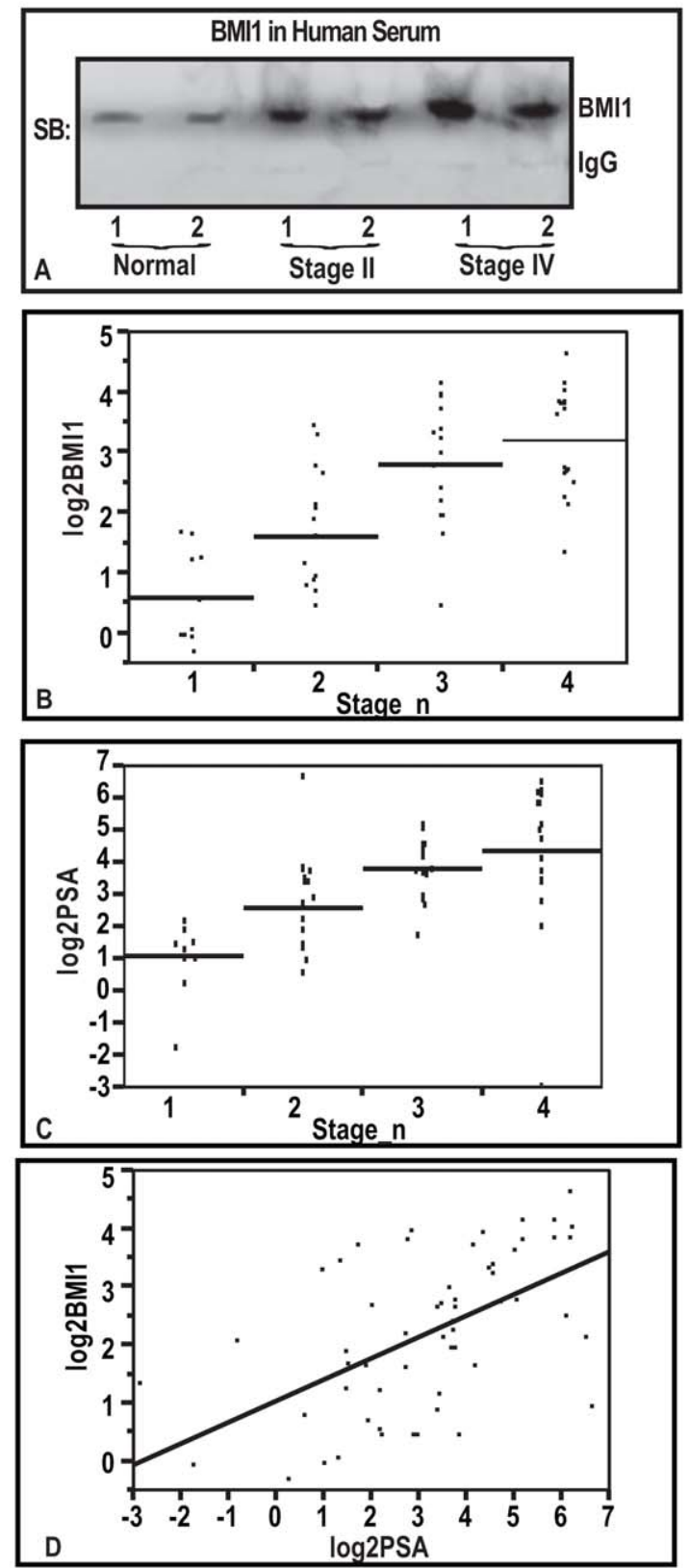

Figure 4. Measurement of serum-BMI1 protein levels in human CaP patients. (A) Figure represents the detection of BMI1 in human serum as assessed by Slot-blot analyses. The blot data shown here are representative of three samples. (B) Plot of BMI1 ( $\mathrm{ng} / \mathrm{ml}$, log-2) versus CaP group rank $(n=58)$. Horizontal line is the group mean. (C) Plot of PSA ( $\mathrm{ng} / \mathrm{ml}$, log-2) versus CaP group rank $(n=58)$. Horizontal line is the group mean. Each group (Fig. F \& G) represented as $1=$ Normal, $2=$ Stage II, 3 = Stage III, and $4=$ Stage IV CaP. (D) Figure represents the correlation between serum-PSA ( $\mathrm{ng} / \mathrm{ml}, \log -2)$ and serum-BMI $1(\mathrm{ng} / \mathrm{ml}$, $\log -2)$ (Spearman $r=0.58, p<0.001)$ in 58 men. Line is from simple linear regression.

doi:10.1371/journal.pone.0052993.g004 
Table 1. Serum-BMI1 protein levels in human prostate cancer patients.

\begin{tabular}{|c|c|c|c|c|}
\hline \multirow[b]{2}{*}{ Stage } & \multirow[b]{2}{*}{ Number of Human Subjects } & \multicolumn{2}{|l|}{ ng/ml serum } & \multirow[b]{2}{*}{ Average GS } \\
\hline & & PSA (mean \pm SE) & BMI1 (mean \pm SE) & \\
\hline Normal & 10 & $2.60 \pm 0.54$ & $1.72 \pm 0.30$ & None \\
\hline Stage II & 16 & $12.82 \pm 9.67$ & $3.91 \pm 0.60^{*}$ & $6.0 \pm 0.092$ \\
\hline Stage III & 15 & $16.77 \pm 3.91^{*}$ & $8.55 \pm 1.95^{*}$ & $6.9 \pm 0.12$ \\
\hline Stage IV & 17 & $38.04 \pm 12.15^{*}$ & $10.84 \pm 2.44^{*}$ & $7.8 \pm 0.40$ \\
\hline
\end{tabular}

shown) and colon HT29 cells (data not shown). The ELISA data of secretory BMIl conforms to our observations in immunhistochemical analysis of $\mathrm{CaP}$ tissue specimens where we observed an increased stromal staining for BMIl protein. This would be the first report showing BMIl as a secretory protein from tumor cells.

\section{Secreted BMI1 in the culture media is directly related to intracellular BMI1 of tumor cells}

Since BMIl was observed to secrete in the culture media, we sought to determine if this secretion is related to intracellular BMIl. We employed a two-way approach where BMIl was either knocked-down or overexpressed in CaP cells. After $24 \mathrm{~h}$ post transfection, BMI1-suppressed and BMI1-overexpressed cells were cultured in the serum-free media for further $24 \mathrm{~h}$. Next, serum free media from transfected cell cultures were harvested and analyzed for BMI protein by employing an ELISA. BMI1 protein levels were observed to be highly reduced in BMI1-knocked-down cells and increased in BMIl-overexpressed cells (Fig. 3A-F; p<0.05). These data show that BMIl-silenced tumor cells significantly secrete low levels of BMIl protein and BMIl-overexpressed CaP cells secreted significantly high levels of BMI 1 protein in the culture media, the data suggest that intracellular BMI 1 is directly correlated with the secretory BMI1 protein levels (Fig. 3A-F; $\mathrm{p}<0.05)$. We speculate that increase in the intracellular BMI levels in CaP cells amounts to its subsequent release by epithelial cells into the extracellular space and causes a spike in the secretory BMIl protein levels.

\section{BMI1 expression in cells representing CaP in Caucasian and African-American men is independent of influence of androgen}

The differences between races in androgen concentrations and sensitivity are considered as important factors for the racial disparities in $\mathrm{CaP}$ [20]. However, androgen concentrations do not always correlate to PSA in cancer patients and sometimes mislead the outcome [21]. We next asked if the BMIl levels in humans $\mathrm{CaP}$ disease has a correlation with presence or absence of androgen. For this purpose we selected VCaP (representing androgen-independent CRPC phenotype in Caucasian population), E006 (representing androgen-dependent non-tumorigenic prostatic epithelial cells from African-American population) and PCa-2b (androgen responsiveness CRPC cells from AfricanAmerican population). Androgen treatment (R1881; $1 \mathrm{nM}$ ) of VCaP, E006, and PCa-2b cells did not cause significant change in the levels of BMIl protein (Fig. 3Gi-ii; p $<0.05$ ) thus suggesting that BMIl expression is independent of androgen status. This data is significant because aggressive $\mathrm{CaP}$ in both Caucasian and African-American is often Androgen independent [6,19].

\section{Detection of BMI1 protein in blood of human CaP patients}

Since, BMI1 protein was observed to be secreted by human prostatic epithelial cells in vitro. We next asked if BMIl could be detected in the serum of CaP patients. By employing Slot-blot analysis, we determined the levels of BMI 1 protein in albumin-free cleared sera, prepared from human blood (randomly selected from normal and $\mathrm{CaP}$ patients). As evident from the Fig. 4A, BMI 1 protein was detected in the serum of $\mathrm{CaP}$ patients.

\section{Serum-BMI1 protein levels increase progressively with $\mathrm{CaP}$ development in human patients}

We next asked if serum-BMI 1 protein levels bear translational relevance as a potential biomarker for staging and development of $\mathrm{CaP}$ disease in humans. For this purpose we investigated if serumBMI1 protein levels exhibit a significant difference with respect to different stages of CaP. We determined serum-BMIl levels in a cohort of 58 human subjects representing normal disease free condition, and different CaP stages, viz., normal $(\mathrm{n}=10)$, Stage II $\mathrm{CaP}(\mathrm{n}=16)$, Stage III CaP $(\mathrm{n}=15)$, and Stage IV CaP $(\mathrm{n}=17)$. The average serum-BMIl protein levels in normal human subjects $(\mathrm{n}=10)$ were estimated to be approximately $1.72 \pm 0.30 \mathrm{ng} / \mathrm{ml}$ of serum (Table 1). The serum BMIl level for each patient is provided in Table 2. Serum-BMIl levels were lower in normal human subjects than in CaP patients. BMIl protein levels in human $\mathrm{CaP}$ patients was $3.91 \pm 0.60 \mathrm{ng} / \mathrm{ml}$ in stage II CaP, $8.55 \pm 1.95 \mathrm{ng} / \mathrm{ml}$ in stage III CaP and $10.84 \pm 2.44 \mathrm{ng} / \mathrm{ml}$ in stage IV CaP (Table 1). These data showed that mean serumBMI1 protein levels were progressively increased with increasing stage of $\mathrm{CaP}$ disease in humans $(\mathrm{r}=0.72, \mathrm{p}<0.001$, Fig. $4 \mathrm{~B})$. These data suggest that serum-BMI 1 protein levels possess a translational potential to be developed as a novel serum-biomarker for $\mathrm{CaP}$ disease however further studies in a large cohort of patients are warranted.

\section{Serum-BMI1 protein levels were correlated with serum PSA levels}

Next we investigated if an increase in BMIl during CaP developments has a correlation with PSA levels in these patients $(\mathrm{n}=58)$. In this Cohort of CaP patients, association of PSA with progression of $\mathrm{CaP}$ was also observed $(\mathrm{r}=0.57, \mathrm{p}<0.001$, Fig. $4 \mathrm{C})$. The serum PSA level for each patient is provided in Table 2. BMI1 was modestly correlated with PSA $(r=0.58, p<0.001$, Fig. 4D). BMI1 remained significantly $(\mathrm{p}<0.001)$ when adjusting for PSA in a regression model predicting cancer stage group. 
Table 2. Comparative analysis of serum-PSA and serum-BMI1 in prostate cancer patients vis-à-vis Gleason score.

\begin{tabular}{|c|c|c|c|c|c|c|c|c|c|c|c|c|}
\hline \multirow[b]{2}{*}{ S.N. } & \multirow[b]{2}{*}{ Age } & \multirow[b]{2}{*}{ Stages } & \multirow[b]{2}{*}{ GS } & \multirow[b]{2}{*}{ DA } & \multirow[b]{2}{*}{ MS } & \multicolumn{3}{|c|}{ Therapy } & \multirow[b]{2}{*}{ Serum collected during } & \multirow[b]{2}{*}{ CaP Type } & \multicolumn{2}{|c|}{$\mathrm{ng} / \mathrm{ml}$ serum } \\
\hline & & & & & & CT & RT & HT & & & PSA & BMI1 \\
\hline 1 & 78 & - & - & - & - & - & - & - & - & - & 1.18 & 0.81 \\
\hline 2 & 57 & - & - & - & - & - & & - & - & - & 2.8 & 3.2 \\
\hline 3 & 66 & - & - & - & - & - & - & - & - & - & 4.43 & 2.32 \\
\hline 4 & 70 & - & - & - & - & - & & - & - & - & 3.63 & 3.09 \\
\hline 5 & 65 & - & - & - & - & - & - & - & - & - & 2.01 & 0.97 \\
\hline 6 & 80 & - & - & - & - & - & & - & - & - & 2.02 & 0.97 \\
\hline 7 & 78 & - & - & - & - & - & - & - & - & - & 0.29 & 0.94 \\
\hline 8 & 57 & - & - & - & - & - & & - & - & - & 2.45 & 1.02 \\
\hline 9 & 66 & - & - & - & - & - & - & - & - & - & 2.72 & 2.37 \\
\hline 10 & 70 & - & - & - & - & - & & - & - & - & 4.51 & 1.46 \\
\hline 11 & 73 & ॥ & $3+3$ & 71 & $\mathrm{~N}$ & $\mathrm{~N}$ & $\mathrm{Y}$ & $\mathrm{N}$ & Remission & $A C$ & 10.38 & 3.83 \\
\hline 12 & 73 & $\|$ & $3+3$ & 51 & $\mathrm{~N}$ & $\mathrm{~N}$ & $Y$ & Y & Treatment & $A C$ & 11.27 & 4.39 \\
\hline 13 & 83 & $\|$ & $3+3$ & 77 & $\mathrm{~N}$ & Y & $\mathrm{N}$ & $Y$ & Treatment & $A C$ & 2.51 & 10.96 \\
\hline 14 & 74 & $\|$ & $3+3$ & 73 & $\mathrm{~N}$ & $\mathrm{~N}$ & Y & $\mathrm{N}$ & Treatment & $A C$ & 13.51 & 4.24 \\
\hline 15 & 70 & $\|$ & $3+3$ & 57 & $\mathrm{~N}$ & $\mathrm{~N}$ & Y & Y & Remission & $A C$ & 1.48 & 3.72 \\
\hline 16 & 82 & $\|$ & $3+3$ & 79 & $\mathrm{~N}$ & $\mathrm{~N}$ & Y & Y & Treatment & $A C$ & 13.39 & 4.83 \\
\hline 17 & 72 & II & $3+3$ & 71 & $\mathrm{~N}$ & $\mathrm{~N}$ & $\mathrm{~N}$ & $\mathrm{Y}$ & Remission & $A C$ & 0.57 & 2.16 \\
\hline 18 & 72 & $\|$ & $3+2$ & 51 & $\mathrm{~N}$ & $\mathrm{~N}$ & Y & $\mathrm{N}$ & Treatment & $A C$ & 6.62 & 3.04 \\
\hline 19 & 81 & II & $3+3$ & 77 & $\mathrm{~N}$ & Y & $\mathrm{Y}$ & Y & Treatment & $A C$ & 10.56 & 2.24 \\
\hline 20 & 57 & II & $3+3$ & 57 & $\mathrm{~N}$ & $\mathrm{~N}$ & $\mathrm{~N}$ & $\mathrm{~N}$ & Detection & $A C$ & 1.91 & 7.80 \\
\hline 21 & 60 & ॥ & $3+3$ & 60 & $\mathrm{~N}$ & $\mathrm{~N}$ & $\mathrm{~N}$ & $\mathrm{~N}$ & Detection & $A C$ & 4.62 & 2.37 \\
\hline 22 & 64 & $\|$ & $3+3$ & 60 & $\mathrm{~N}$ & $\mathrm{~N}$ & $\mathrm{~N}$ & Y & Treatment & $A C$ & 3.75 & 2.61 \\
\hline 23 & 75 & $\|$ & $4+3$ & 75 & $\mathrm{~N}$ & $\mathrm{~N}$ & $\mathrm{~N}$ & $\mathrm{~N}$ & Detection & $A C$ & 2.72 & 1.37 \\
\hline 24 & 47 & $\|$ & $3+3$ & 47 & $\mathrm{~N}$ & $\mathrm{~N}$ & $\mathrm{~N}$ & $\mathrm{~N}$ & Detection & AC & 14.45 & 2.89 \\
\hline 25 & 58 & $\|$ & $3+3$ & 58 & $\mathrm{~N}$ & Y & $\mathrm{N}$ & Y & Treatment & $A C$ & 19.91 & 2.35 \\
\hline 26 & 63 & $\|$ & $3+3$ & 63 & $\mathrm{~N}$ & $\mathrm{~N}$ & $\mathrm{~N}$ & $\mathrm{~N}$ & Detection & $A C$ & 25.33 & 3.67 \\
\hline 27 & 72 & III & $3+4$ & 66 & $\mathrm{~N}$ & $\mathrm{~N}$ & Y & $Y$ & Remission & $A C$ & 13.04 & 5.26 \\
\hline 28 & 78 & III & $4+3$ & 77 & $\mathrm{~N}$ & $\mathrm{~N}$ & $\mathrm{~N}$ & $\mathrm{Y}$ & Treatment & $A C$ & 35.87 & 17.52 \\
\hline 29 & 67 & III & $3+3$ & 62 & $\mathrm{~N}$ & $\mathrm{~N}$ & Y & $\mathrm{N}$ & Remission & $A C$ & 7.02 & 15.49 \\
\hline 30 & 73 & III & $3+4$ & 67 & $\mathrm{~N}$ & $\mathrm{~N}$ & Y & Y & Remission & $A C$ & 3.30 & 13.23 \\
\hline 31 & 77 & III & $4+4$ & 73 & $\mathrm{~N}$ & $\mathrm{~N}$ & $\mathrm{~N}$ & Y & Treatment & $A C$ & 20.06 & 15.30 \\
\hline 32 & 69 & III & $4+3$ & 64 & $\mathrm{~N}$ & $\mathrm{~N}$ & Y & Y & Remission & $A C$ & 23.16 & 9.39 \\
\hline 33 & 70 & III & $3+4$ & 66 & $\mathrm{~N}$ & $\mathrm{~N}$ & Y & Y & Remission & $A C$ & 21.83 & 10.01 \\
\hline 34 & 73 & III & $3+3$ & 77 & $\mathrm{~N}$ & $\mathrm{~N}$ & $\mathrm{~N}$ & Y & Treatment & $A C$ & 33.35 & 6.79 \\
\hline 35 & 65 & III & $4+3$ & 62 & $\mathrm{~N}$ & $\mathrm{~N}$ & Y & $\mathrm{N}$ & Remission & $A C$ & 12.29 & 7.95 \\
\hline 36 & 68 & III & $3+4$ & 66 & $\mathrm{~N}$ & $\mathrm{~N}$ & $\mathrm{~N}$ & Y & Treatment & $A C$ & 6.45 & 4.56 \\
\hline 37 & 70 & III & $3+4$ & 69 & $\mathrm{~N}$ & $\mathrm{~N}$ & $\mathrm{~N}$ & Y & Treatment & AC & 7.70 & 4.37 \\
\hline 38 & 60 & III & $3+4$ & 60 & $\mathrm{~N}$ & $\mathrm{~N}$ & $\mathrm{Y}$ & $\mathrm{N}$ & Treatment & $A C$ & 12.72 & 3.86 \\
\hline 39 & 54 & III & $3+4$ & 54 & $\mathrm{~N}$ & $\mathrm{~N}$ & $\mathrm{~N}$ & $\mathrm{~N}$ & Detection & $A C$ & 23.18 & 7.51 \\
\hline 40 & 65 & III & $4+3$ & 65 & $\mathrm{~N}$ & $\mathrm{~N}$ & $\mathrm{~N}$ & $\mathrm{~N}$ & Detection & $A C$ & 13.54 & 3.83 \\
\hline 41 & 57 & III & $4+3$ & 57 & $\mathrm{~N}$ & Y & $\mathrm{N}$ & Y & Treatment & $A C$ & 18.08 & 3.13 \\
\hline 42 & 69 & IV & $3+3$ & 66 & $\mathrm{~N}$ & N & $\mathrm{N}$ & Y & Remission & $A C$ & 35.96 & 14.02 \\
\hline 43 & 85 & IV & $4+4$ & 80 & $\mathrm{~N}$ & $\mathrm{~N}$ & $\mathrm{~N}$ & Y & Treatment & $A C$ & 57.67 & 17.69 \\
\hline 44 & 52 & IV & $9+0$ & 51 & $\mathrm{Li}, \mathrm{L}$ & Y & Y & Y & Treatment & $A C$ & 32.07 & 12.21 \\
\hline 45 & 68 & IV & $3+4$ & 64 & $\mathrm{~N}$ & $\mathrm{~N}$ & Y & $\mathrm{Y}$ & Remission & $A C$ & 57.64 & 14.29 \\
\hline 46 & 80 & IV & $4+4$ & 76 & $\mathrm{~N}$ & $\mathrm{~N}$ & Y & Y & Treatment & AC & 74.57 & 16.34 \\
\hline 47 & 57 & IV & $6+4$ & 53 & $\mathrm{Li}$ & Y & $\mathrm{N}$ & Y & Treatment & $A C$ & 67.97 & 5.59 \\
\hline 48 & 76 & IV & $3+3$ & 65 & $\mathrm{~N}$ & $Y$ & $\mathrm{~N}$ & $Y$ & Treatment & $\mathrm{AC}$ & 89.70 & 4.33 \\
\hline
\end{tabular}


Table 2. Cont.

\begin{tabular}{|c|c|c|c|c|c|c|c|c|c|c|c|c|}
\hline \multirow[b]{2}{*}{ S.N. } & \multirow[b]{2}{*}{ Age } & \multirow[b]{2}{*}{ Stages } & \multirow[b]{2}{*}{ GS } & \multirow[b]{2}{*}{ DA } & \multirow[b]{2}{*}{ MS } & \multicolumn{3}{|c|}{ Therapy } & \multirow[b]{2}{*}{ Serum collected during } & \multirow[b]{2}{*}{ CaP Type } & \multicolumn{2}{|c|}{ ng/ml serum } \\
\hline & & & & & & CT & RT & HT & & & PSA & BMI1 \\
\hline 49 & 74 & IV & $2+1$ & 74 & B & $\mathrm{N}$ & $\mathrm{Y}$ & $\mathrm{Y}$ & Treatment & $A C$ & 25.91 & 6.71 \\
\hline 50 & 73 & IV & $6+2$ & 62 & $B, L$ & $\mathrm{~N}$ & $\mathrm{Y}$ & $\mathrm{Y}$ & Treatment & $A C$ & 17.27 & 13.23 \\
\hline 51 & 70 & IV & $4+5$ & 70 & $\mathrm{~N}$ & $\mathrm{~N}$ & $\mathrm{~N}$ & $\mathrm{~N}$ & Treatment & $A C$ & 71.32 & 24.89 \\
\hline 52 & 47 & IV & $4+4$ & 46 & $\mathrm{~N}$ & Y & $\mathrm{N}$ & $\mathrm{Y}$ & Treatment & $A C$ & 6.78 & 14.09 \\
\hline 53 & 60 & IV & $4+5$ & 60 & $\mathrm{~N}$ & $\mathrm{~N}$ & $\mathrm{~N}$ & $\mathrm{~N}$ & Detection & $A C$ & 0.25 & 3.50 \\
\hline 54 & 59 & IV & $3+5$ & 59 & $\mathrm{~N}$ & $\mathrm{~N}$ & $\mathrm{~N}$ & $\mathrm{~N}$ & Detection & $A C$ & 11.0 & 6.58 \\
\hline 55 & 72 & IV & $4+5$ & 72 & $\mathrm{~N}$ & $\mathrm{~N}$ & $\mathrm{~N}$ & $\mathrm{~N}$ & Detection & $A C$ & 13.16 & 4.79 \\
\hline 56 & 63 & IV & $5+4$ & 63 & $\mathrm{~N}$ & $\mathrm{~N}$ & $\mathrm{~N}$ & $\mathrm{~N}$ & Detection & $A C$ & 4.02 & 5.39 \\
\hline 57 & 75 & IV & $4+3$ & 73 & $\mathrm{~N}$ & $\mathrm{~N}$ & Y & $\mathrm{N}$ & Treatment & $A C$ & 10.35 & 6.30 \\
\hline 58 & 75 & IV & $4+4$ & 64 & $\mathrm{~N}$ & $\mathrm{~N}$ & $\mathrm{~N}$ & $\mathrm{Y}$ & Treatment & $A C$ & 71.16 & 14.41 \\
\hline
\end{tabular}

$\mathrm{N}$ represents NO; $\mathrm{Y}$ represents Yes; $\mathrm{AC}$ represents adenocarcinoma; $\mathrm{CaP}$ represents prostate cancer; GS represents Gleason score; DA represents diagnosis age; $\mathrm{MS}$ represents metastatic site; CT represents chemotherapy; RT represents radiation therapy, HT represents hormonal therapy; $L$ represents lung; Li represents Liver ; B represents bone; Bold and italic represent values in patients with low PSA and high BMI1 levels.

doi:10.1371/journal.pone.0052993.t002

\section{Discussion}

A prognostic biomarker provides evidence about a patient's eventual outcomes from a disease independent of a given therapy, whereas a predictive-biomarker estimates the likelihood of response/benefit to a specific therapy in a specific context [22]. PSA still remains the marker of choice for CaP diagnosis, prognosis, and active surveillance. However, PSA has several limitations [23-26]. For example, sipuleucel-T is known to improve survival without having an impact on early PSA levels [27]. PSA progression during GRPC therapy is reported to be prognostic for overall survival but likewise is not a surrogate for overall survival [22]. Some $\mathrm{CaP}$ types such as neuroendocrine tumors, produce little if any PSA and decreased secretion of PSA in patients suffering from ductal $\mathrm{CaP}$ has also been reported $[23,25]$. In these cases, PSA alterations do not correlate well with clinical benefit $[23,25]$. There is an unmet need to identify a robust and reliable biomarker which can detect disease progression in patients in whom PSA is not a reliable indicator. Thus, the development of biomarker(s) that can correlate with disease stage along the course of tumor progression is important for intervention and treatment of disease, especially chemoresistant CaP.

In the current study, we provide evidence that BMIl secretory protein has high potential to be developed as a reliable serumbiomarker for human CaP. We provide compelling evidence that BMIl protein is (i) secreted by tumor cells in greater amounts proportionate to tumor stage and grade, (ii) detectable in blood of human $\mathrm{CaP}$ patients in an order of increasing tumor/Gleason Score grade and, (iii) detectable in some $\mathrm{CaP}$ patients which exhibit very low levels. Further, we showed a good correlation $(\mathrm{r}=0.58)$ between secretory-PSA and secretory-BMIl in the serum of human $\mathrm{CaP}$ patients. Thus, expression of PSA, along with the detection of BMI 1 in serum and biopsy tissue samples, may offer a new approach for $\mathrm{CaP}$ diagnosis, prognosis, and active surveillance. We suggest that serum-BMIl could bring under surveillance some cases in which PSA levels do not correlated with disease progression.

African-American men exhibit the worst prognosis of CaP disease which could be due to several reasons [20,28-29]. It is being suggested that absence of a reliable predictive biomarker for African American $\mathrm{CaP}$ is one of the contributory factors for the failure of prognosis in African-American $\mathrm{CaP}$ patients. Clinical studies suggested significant differences and in the levels of PSA of between Caucasian and African-American CaP patients [20]. PSA is androgen-dependent and its expression is regulated by androgen receptor [30]. The difference in androgen concentrations between African-American and Caucasian is considered as important factor for the racial disparities in CaP prognosis [20]. It has been reported that androgen receptor expression is $81 \%$ higher in African-American $\mathrm{CaP}$ patients that in Caucasian and high androgen receptor stimulation has been considered as one of the reasons for $\mathrm{CaP}$ development at a younger age with rapid progress in African-American men [29]. Changes in PSA may be informative in patients treat with anti-androgen therapy. However, changes in serum-PSA do not always predict the action of therapy or the disease condition [27,31-33]. Furthermore, in neuroendocrine or small cell prostate cancer, very little or no PSA is produced, and therefore PSA changes do not correlate with disease status [33]. Thomson et al. [34] reported that $\mathrm{CaP}$ can be detected in approximately $15 \%$ of men with normal or low levels of total PSA level. This data questions the validity of PSA as a global serum-biomarker for men. Our study in this context is significant as we provide evidence that BMIl could be a reliable predictive secretory biomarker for both the races especially African-American CaP. This is evident from our data we show that E006 cell (derived from African American CaP patient) does not express PSA [14], however secrete BMI1 in culture media (Fig. 2D). Notably, E006 cell line also expressed intracellular BMI1 (Fig. 2B). This data suggest that BMIl could be used as a biomarker for even those cases in African-American men who exhibit very low PSA levels but develop CaP disease. This corroborates to our data in Caucasian men, where we were able to detect BMI in patients which exhibited very low PSA levels (Table 2). Furthermore, BMI was found to independent of androgen and thus, it may be very useful as a prognostic biomarker in patients with both early as well as advanced prostate cancer.

Thus, analysis of BMII in tissue biopsies and serum analysis may serve as a prognostic biomarker in $\mathrm{CaP}$ and may ultimately lead to monitoring therapeutic response during CaP treatment protocols. We suggest that BMI stands out as a promising molecule to be developed as an ideal serum-biomarker for 
prognosis of $\mathrm{CaP}$ in humans. We suggest that this study has high translational potential however, warrants further investigation in a big cohort of human patients. It is imperative that BMI1 as a biomarker be studied rigorously in parallel with drug development (which is underway in our laboratory), given the potential to maximize benefit and management of $\mathrm{CaP}$ disease in Caucasian as well as African-American patients, that in turn will minimize the harms and costs to society.

\section{References}

1. Siegel R, Naishadham D, Jemal A (2012) Cancer statistics. CA Cancer J Clin 62:10-29.

2. Bickers B, Aukim-Hastie C (2009) New molecular biomarkers for the prognosis and management of prostate cancer-the post PSA era. Anticancer Res 29: 3289 3298.

3. Levy DA, Jones JS (2011) Management of rising prostate-specific antigen after a negative biopsy. Curr Urol Rep 12: 197-202.

4. Meulenbeld HJ, Bleuse JP, Vinci EM, Raymond E, Vitali G, et al. (2012) Randomized phase II study of danusertib in patients with metastatic castrationresistant prostate cancer after docetaxel failure. BJU Int. doi: 10.1111/j.1464410X.2012.11404.x.

5. Casanova-Salas I, Rubio-Briones J, Fernández-Serra A, López-Guerrero JA (2012) miRNAs as biomarkers in prostate cancer. Clin Transl Oncol PMID: 22855165.

6. Madu CO, Lu Y (2010) Novel diagnostic biomarkers for prostate cancer. J Cancer; 1:150-177.

7. Fowler JE Jr, Bigler SA, Farabaugh PB (2002) Prospective study of cancer detection in black and white men with normal digital rectal examination but prostate specific antigen equal or greater than $4.0 \mathrm{ng} / \mathrm{mL}$. Cancer 94:16611671 .

8. Siddique HR, Saleem M (2012) Role of BMI1, a Stem Cell Factor in Cancer Recurrence and Chemoresistance: Preclinical and Clinical Evidences. Stem Cells 30: 372-378.

9. Kang MK, Kim RH, Kim SJ, Yip FK, Shin KH, et al. (2007) Elevated BMI1 expression is associated with dysplastic cell transformation during oral carcinogenesis and is required for cancer cell replication and survival. Br J Cancer 96: 126-133.

10. Cenci T, Martini M, Montano N, D'Alessandris QG, Falchetti ML, et al. (2012) Prognostic Relevance of c-Myc and BMI1 Expression in Patients With Glioblastoma. Am J Clin Pathol 138: 390-396.

11. Campbell PM, Groehler AL, Lee KM, Ouellette MM, Khazak V, et al. (2007) $\mathrm{K}$-Ras promotes growth transformation and invasion of immortalized human pancreatic cells by Raf and phosphatidylinositol 3-kinase signaling. Cancer Res 67: 2098-2106.

12. Hayward SW, Wang Y, Cao M, Hom YK, Zhang B, et al. (2001) Malignant transformation in a nontumorigenic human prostatic epithelial cell line. Cancer Res 61:8135-8142.

13. Theodore S, Sharp S, Zhou J, Turner T, Li H, et al. (2010) Establishment and characterization of a pair of non-malignant and malignant tumor derived cell lines from an African American prostate cancer patient. Int J Oncol 37:14771482 .

14. Koochekpour S, Maresh GA, Katner A, Parker-Johnson K, Lee TJ, et al. (2004) Establishment and characterization of a primary androgen-responsive AfricanAmerican prostate cancer cell line, E006AA. Prostate 60: 141-152.

15. Saleem M, Adhami VM, Zhong W, Longley BJ, Lin CY, et al. (2006) A novel biomarker for staging human prostate adenocarcinoma: overexpression of matriptase with concomitant loss of its inhibitor, hepatocyte growth factor activator inhibitor-1. Cancer Epidemiol Biomarkers Prev 15: 217-227.

16. Siddique HR, Liao DJ, Mishra SK, Schuster T, Wang L, et al. (2012) Epicatechin-rich cocoa polyphenol inhibits Kras-activated pancreatic ductal carcinoma cell growth in vitro and in a mouse model. Int J Cancer 131: 17201731 .

\section{Author Contributions}

Conceived and designed the experiments: MS. Performed the experiments: HRS AP WZ EJB. Analyzed the data: HRS RJK BRK EJB MS. Contributed reagents/materials/analysis tools: MS SK JSR. Wrote the paper: HRS.

17. Siddique HR, Mishra SK, Karnes RJ, Saleem M (2011) Lupeol, a novel androgen receptor inhibitor: implications in prostate cancer therapy. Clin Cancer Res 17: 5379-5391.

18. Glinsky GV, Berezovska O, Glinskii AB (2005) Microarray analysis identifies a death-from-cancer signature predicting therapy failure in patients with multiple types of cancer. J Clin Invest 115:1503-1521.

19. Parray A, Siddique HR, Nanda S, Konety BR, Saleem M (2012) Castrationresistant prostate cancer: potential targets and therapies. Biologics 6: 267-276.

20. Bigler SA, Pound GR, Zhou X (2011) A retrospective study on pathologic features and racial disparities in prostate cancer. Prostate Cancer 2011:239460.

21. Asbell SO, Raimane KC, Montesano AT, Zeitzer KL, Asbell MD, et al. (2000) Prostate-specific antigen and androgens in African-American and white normal subjects and prostate cancer patients. J Natl Med Assoc 92: 445-449.

22. Armstrong AJ, Eisenberger MA, Halabi S, Oudard S, Nanus DM, et al. (2012) Biomarkers in the Management and Treatment of Men with Metastatic Castration-Resistant Prostate Cancer. Eur Urol 61: 549-559.

23. Sasaki T, Komiya A, Suzuki H, Shimbo M, Ueda T, et al. (2005) Changes in chromogranin a serum levels during endocrine therapy in metastatic prostate cancer patients. Eur Urol 48: 224-9.

24. Shariat SF, Semjonow A, Lilja H, Savage C, Vickers AJ, et al. (2011) Tumor markers in prostate cancer I: blood-based markers. Acta Oncol 50: 61-75.

25. Spiess PE, Pettaway CA, Vakar-Lopez, Kassouf W, Wang X, et al. (2007) Treatment outcomes of small cell carcinoma of the prostate: a single-center study. Cancer 110: 1729-1737.

26. Fradet Y (2009) Biomarkers in prostate cancer diagnosis and prognosis: beyond prostate-specific antigen. Curr Opin Urol 19: 243-246.

27. Kantoff PW, Higano CS, Shore ND, Berger ER, Small EJ, et al. (2010) Sipuleucel-T immunotherapy for castration-resistant prostate cancer. N Engl J Med 363: 411-422.

28. Smith DS, Carvalhal GF, Mager DE, Bullock AD, Catalona WJ (1998) Use of lower prostate specific antigen cutoffs for prostate cancer screening in black and white men. J Urol 160: 1734-1738.

29. Gaston KE, Kim D, Singh S, Ford OH, Mohler JL (2003) Racial differences in androgen receptor protein expression in men with clinically localized prostate cancer. J Urol 170: 990-993.

30. Balk SP, Ko YJ, Bubley GJ (2003) Biology of prostate-specific antigen. J Clin Oncol 21: 383-391.

31. Armstrong AJ, Garrett-Mayer E, Ou Yang YC, et al. (2007) Prostate-specific antigen and pain surrogacy analysis in metastatic hormone-refractory prostate cancer. J Clin Oncol 25:3965-3970.

32. Petrylak DP, Ankerst DP, Jiang CS, Tangen CM, Hussain MH, et al. (2006) Evaluation of prostate-specific antigen declines for surrogacy in patients treated on SWOG 99-16. J Natl Cancer Inst 98:516-521.

33. Taplin ME, George DJ, Halabi S, Sanford B, Febbo PG, et al. (2005) Prognostic significance of plasma chromogranin a levels in patients with hormonerefractory prostate cancer treated in Cancer and Leukemia Group B 9480 study. Urology 66: 386-391.

34. Thompson IM, Pauler DK, Goodman PJ, Tangen CM, Lucia MS, et al. (2004) Prevalence of prostate cancer among men with a prostate-specific antigen level $<$ or $=4.0$ ng per milliliter. N Engl J Med 350: 2239-2246. 